\title{
POLÍTICAS DE GESTÃO DO SISTEMA PRODUTIVO: UMA RESPOSTA POSSÍVEL DO ESTADO À CRISE BRASILEIRA*
}

\author{
José Carlos Miranda \\ José Ricardo Tauile (in memoriam) ${ }^{2}$ \\ Lia Haguenauer (in memoriam) ${ }^{3}$
}

De cacos, de buracos de hiatos e de vácuos de elipses, psius faz-se, desfaz-se, faz-se uma incorpórea face, resumo do exist(ir)

Carlos Drummond de Andrade

\section{APRESENTAÇÃO**}

José Carlos Miranda

Que me desculpe nosso poeta maior, mas desloquei, do passado para o presente, o último verbo de sua estrofe para falar de Lia. Ela é a mestra que, por sabedoria e pudor, sempre se faz companheira de turma. Com humildade alicerça, nos anos 1970, as bases de nossos sistemas de classificação de estatísticas industriais e de contabilidade social, cooperando com o Professor Isaac Kerstenetzky na refundação de nosso prestigioso IBGE.

Juntando cacos e tapando buracos passamos nossos dias ao redor de uma enorme mesa de trabalho, na Rua Equador, alocando laminados a frio, peças e componentes de tornos mecânicos, artigos de passamanaria e tantos outros produtos, que sequer tínhamos ouvido falar, a seus respectivos setores, subsetores e a quantos mais níveis

\footnotetext{
* Versão adaptada da exposição feita durante seminário realizado em São Paulo/SP, nos dias 15 e 16 de abril de 1989, posteriormente transcrita e publicada na íntegra em WEFFORT, F. (org.) PT: Um Projeto para o Brasil. São Paulo: Editora Brasiliense, 1989, p. 127-159.

${ }^{1}$ Economista e, à época, professor do Instituto de Economia da Universidade Estadual de Campinas.

${ }^{2}$ Economista e, à época, professor do Instituto de Economia Industrial da Universidade Federal do Rio de Janeiro.

${ }^{3}$ Economista e, à época, pesquisadora do Instituto de Economia Industrial da Universidade Federal do Rio de Janeiro.

** Este texto de apresentação foi incluído por ocasião da republicação do trabalho nesta seção Memória do IE-UFRJ especial, em homenagem aos 10 anos de falecimento de Lia Haguenauer.
} 
de desagregação que a precisão da produção estatística exigisse. Trabalho rotineiro, mas, à época, inovador. De importância despercebida durante sua consecução, mas de grande utilidade pública depois de virar informação disponível para a formulação de políticas que podem mudar o rumo de uma nação.

Espírito público de ética intransigente, Lia defende as metodologias de cálculos de índices de preços e produção quando a arbitrariedade do Poder, então constituído, exige modificações que mascaravam a realidade dos fatos. Revolta-se silenciosamente contra a elipse, contra a omissão de palavras de alguns colegas de profissão. Logo se retira do IBGE e torna-se pesquisadora de nosso Instituto de Economia, onde produz trabalhos seminais sobre a indústria brasileira.

Tão importante quanto o rigor técnico de suas análises sobre a competitividade de nosso sistema manufatureiro é tê-las sempre compatibilizadas com uma proposta abrangente de gestão democrática do capitalismo brasileiro.

Nos anos 1980 ocorre mudança significativa na base tecnológica do sistema industrial que coloca desafios às empresas brasileiras e às nossas políticas públicas. Embora tivéssemos, à época, uma estrutura produtiva complexa e diversificada, estávamos completamente despreparados para entrar na era da produção intensiva em informação e conhecimento. O baixo nível educacional de nossa população, relações trabalhistas obsoletas herdadas do regime autoritário e uma estrutura produtiva voltada ao atendimento do consumo das classes de renda mais elevadas e à exportação de commodities eram óbices à reestruturação de nosso sistema produtivo, necessária à superação daquela década perdida.

Fica claro, para Lia, que adentrar na modernidade tecnológica não depende simplesmente do voluntarismo de empresários inovadores. É, antes de tudo, um projeto de Estado. É uma opção por um modelo de desenvolvimento alternativo ao então vigente que compatibilizasse progresso técnico, crescimento da produção e do emprego, distribuição de renda e bem estar social. Só a partir deste enfoque global do processo de desenvolvimento, ela pode pensar os princípios de uma política planejada de gestão do sistema produtivo brasileiro.

Sua hipótese central é que políticas de estímulo ao investimento e ao consumo das famílias elevariam a oferta doméstica de bens e serviços e ensejariam a elevação da produtividade da indústria brasileira. Garantias de repasse aos salários de parte do aumento da produtividade e políticas de transferências de renda às famílias mais pobres redefiniriam o perfil da demanda interna, garantindo expansão do mercado para as empresas. Às políticas industrial e tecnológica caberiam evitar estrangulamento na estrutura de oferta, compatibilizando-a, ao longo do tempo, com as mudanças no perfil de demanda; criar ambiente propício à promoção de investimentos de ampliação da capacidade e à instalação de novos setores intensivos em tecnologia e conhecimento. Estrategicamente, as políticas de gestão do sistema produtivo deveriam criar condições propícias à disseminação de formas criativas de trabalho, à melhor qualificação da mão de obra como vetores de produtividade sistêmica e inserção competitiva no comércio internacional. 
Estas ideias encontram-se em estado de ebulição em nosso Instituto e no Instituto de Economia da Unicamp, quando Francisco Weffort organiza, em abril de 1989, em São Paulo, o seminário "PT: um projeto para o Brasil", o pontapé inicial da discussão do programa de um possível governo Lula. Lia, José Ricardo Tauile e eu apresentamos a proposta de políticas industrial e tecnológica e tivemos como comentador o prof. Antonio Barros de Castro.

Publicar, nesta edição, uma versão adaptada da exposição feita naquela ocasião é uma homenagem que prestamos a três grandes professores deste Instituto. Criativos, inteligentes e, acima de tudo, generosos com seus companheiros de trabalho e discípulos. Esse artigo faz-nos pensar sobre os hiatos e os vácuos como partes do resumo de existir a que Drummond se refere.

É uma honra conviver com vocês.

\section{POLÍTICAS DE GESTÃO DO SISTEMA PRODUTIVO: UMA RESPOSTA POSSÍVEL DO ESTADO À CRISE BRASILEIRA}

O final da década de 60 foi marcado pelo esgotamento do potencial de inovação e de difusão tecnológica, propulsor da expansão contínua do sistema capitalista no pós-guerra, acarretando uma queda significativa dos níveis de produtividade das principais indústrias dos países desenvolvidos. Os aumentos de produtividade nos países da OCDE passaram a ser menores do que o crescimento do custo do trabalho, pressionando a rentabilidade corrente das empresas. Como consequência da diminuição dos lucros, assistiu-se ao acirramento da concorrência intercapitalista a nível internacional, que afetou, de forma diferenciada, a competitividade das economias nacionais. Neste contexto, o primeiro choque do petróleo de 1973 viria agravar os efeitos da mudança nos termos de troca e pressionar ainda mais a rentabilidade corrente das empresas através dos custos diretos de produção (insumos energéticos e salários). Urgia, assim, um ajustamento na estrutura produtiva dos países centrais que minimizasse sua dependência de indústrias intensivas em energia, que compatibilizasse oferta e demanda de trabalho, que, enfim, repusesse as condições de reprodução do capital.

Consoantes com os objetivos acima, os principais países capitalistas, a partir da segunda metade dos anos 70, passaram a realizar importantes ajustes em suas estruturas produtivas. Estes ajustes enfatizavam:

1) a promoção de indústrias "intensivas em conhecimento" e aquelas ligadas às tecnologias de automação flexível, decorrentes da aplicação dos progressos da microeletrônica e da informática aos processos da mecânica (mecatrônica). Seriam neste âmbito enfatizados os segmentos de bens de capital, robótica, 
informática, telecomunicações e aeronáutica. Ainda no âmbito das indústrias intensivas em conhecimento destacar-se-iam as biotecnologias e os novos materiais;

2) a eliminação de sobrecapacidade das indústrias em declínio como a siderúrgica, a de construção naval e a química pesada;

3) o rejuvenescimento das indústrias tradicionais como a automobilística, têxtil, vestuário, calçados, plástico e borracha.

Do ponto de vista técnico-organizacional do sistema produtivo, este processo de ajustamento estrutural vem requerendo das empresas a adoção de formas alternativas de organização do processo de trabalho (mudança na concepção gerencial, envolvimento do trabalhador com a introdução de progresso técnico e com a qualidade da produção) e de tecnologias de automação flexível. Estas tecnologias respondem às novas características o mercado internacional, mais exigente em termos de qualidade, mais diversificado e sofisticado em termos de demandas específicas, e mais ávido por reduzir ao mínimo necessário o tempo de imobilização do capital-dinheiro em estoques de acabados e de semi-acabados.

As estratégias empresariais de modernização não foram, todavia, por si só, suficientes para viabilizar os ajustes estruturais necessários à recuperação dos níveis de produtividade do capital. Condições político-institucionais particulares foram necessárias para que a renovação da base técnica pudesse propiciar uma redistribuição setorial e social do excedente gerado e dos ganhos de produtividade paulatinamente conquistados, capazes de ratificar ou retificar as estratégias empresariais de médio e longo prazos. A política econômica dos países capitalistas avançados vem exercendo esta função de regular as ações dos agentes econômicos no sentimento de reestruturar o sistema capitalista. Seja ela de caráter neoliberal ou keynesiano, as diferenças situam-se nas respostas às questões para quem e como o processo de reestruturação será efetivado, e não na dicotomia intervencionismo estatal versus atuação das forças de mercado.

Genericamente, a estratégia neoliberal enfatiza a internacionalização das economias nacionais e o mercado exterior como fonte de dinamismo. Concentra a modernização e os ganhos de produtividade nos setores que possuem vantagens comparativas dinâmicas internacionais. Desestabiliza regiões ligadas às indústrias obsoletas. Acelera o processo de desinvestimento em setores públicos tradicionais. Não tem compromisso com o pleno emprego e coloca à margem os grupos sociais e segmentos econômicos não-engajados à modernidade excludente do projeto conservador. Os exemplos mais notórios são Reagan e Thatcher.

Ao contrário, a estratégia keynesiana, compatível com uma gestão democráticoreformista do capitalismo, coloca o mercado interno como motor dinâmico, atentando, também, para os determinantes da competitividade internacional. O importante é o sentido da causalidade: do mercado interno para a inserção competitiva internacional. Enfatiza o papel da alocação setorial dos ganhos de produtividade e da distribuição 
de renda gerada através de ações estruturantes do Estado. Enfim, compatibiliza gestão macroeconômica com políticas sociais e setoriais, uma vez que a política econômica não é neutra em relação aos objetivos dos diversos segmentos sociais.

Após quinze anos de ajustamento estrutural e obedecendo a estratégias diferentes, os principais países da OCDE lograram um esboço para uma nova divisão internacional do trabalho e do capital. Esta questão deve ser observada de dois ângulos: o da concorrência capitalista e das relações inter e intrafirmas, e o da formação de blocos econômicos pela conjuminância ou conflito de interesses político-econômicos dos diversos Estados nacionais.

\section{TENDÊNCIAS DA PRODUÇÃO INDUSTRIAL A NÍVEL MUNDIAL}

As mudanças que vêm se processando na estrutura produtiva capitalista centram-se em três eixos básicos. O primeiro, e mais importante pela sua capilaridade, ocorre a partir dos progressos realizados, nos anos 70 , nas áreas de microeletrônica, sistemas eletrônicos de processamento de dados e de sistemas computadorizados de controle. Estas inovações permitiram: pensar as máquinas-ferramentas e operatrizes como um conjunto de equipamentos flexíveis para a indústria de transformação; utilizar estes equipamentos no desenho e cálculo de projetos de engenharia; e informatizar o setor de serviços que lida ou manipula informações padronizadas.

As tecnologias de automação flexível apontam, também, na direção de mudanças significativas na relação entre divisão do trabalho e extensão de mercado em indústrias como a mecânica, eletrônica, aeronáutica e telecomunicações. Rompidos os limites anteriormente estabelecidos para automação em pequena escala, modificam-se, neste contexto, tanto as formas de organização e de funcionamento do ciclo de produção, quanto as estruturas de mercados onde as empresas expressam seu poder em termos de realização de suas margens de lucro. O segundo núcleo refere-se às mudanças que estão ocorrendo no interior do completo químico, devido à difusão generalizada das inovações das décadas passadas e à emergência da química fina e das biotecnologias. Um terceiro eixo aponta para os novos materiais cerâmicos, ligas metálicas, supercondutores, etc.

$\mathrm{Na}$ indústria de computadores, lato sensu, a partir da produção nos EUA e, cada vez, principalmente no Japão, de microprocessadores com maior densidade e capacidade de memória, a concentração industrial dá-se em forma de leque. O mercado de grandes equipamentos e sistemas é dominado por poucas empresas americanas, japonesas e europeias (lideradas pela IBM), diversificando-se à medida que os equipamentos tornam-se menores (em tamanho e em capacidade de processamento), sendo produzidos por um grande número de empresas menores, inclusive em países menos desenvolvidos, como o Brasil. 
O desenvolvimento de novos equipamentos (hardware) para usos específicos está hoje limitado pela capacidade de geração dos programas (software) respectivos. Em outras palavras, na fronteira da computação eletrônica, o estrangulamento está no software. Com o hardware, que já existe, há muito espaço para o desenvolvimento de novos produtos. De um lado, mesmo nos países desenvolvidos, a demanda pela produção de software está insatisfeita, revelando um promissor e valorizador segmento do mercado de trabalho, e por outro lado, mesmo em países em desenvolvimento, existe engenhosidade para este tipo de produção.

A revolução tecnológica operada nos bens de capital pela síntese mecânicoeletrônica teve, também, como decorrência, já em princípios dos anos 80, o rejuvenescimento de setores considerados maduros como o automobilístico, têxtil, vestuário, borracha, plástico, etc., no Japão, Alemanha Ocidental, Itália, por exemplo. A capacidade ofensiva da mecatrônica e da robótica, através da promoção e difusão rápida da inovação tecnológica e da aceleração da obsolescência dos produtos é outra face da maior flexibilidade que vem adquirindo o sistema produtivo dos países desenvolvidos. Esta flexibilidade passa pela redefinição da divisão do trabalho inter e intra-empresas no interior dos circuitos produtivos das diversas indústrias.

O mercado de equipamentos para telecomunicações teve seu desenvolvimento caracterizado por um alto grau de concentração. Este ocorria tanto a nível internacional, onde quatro empresas (Western Electric, ITT, Siemens, Ericsson) detinham, em 1980, 66\% do mercado, quanto a níveis nacionais, onde, geralmente, as quatro maiores empresas detinham $80 \%$ do mercado. Existem, entretanto, evidencias de mudanças deste quadro. $\mathrm{Na}$ área de transmissão, por exemplo, a emergência de novas tecnologias encorajou a entrada de produtores que, tradicionalmente, não operavam neste segmento de mercado, com os produtores de equipamentos para rádio, de satélites, de vidro e laser. Houve, também, uma acelerada convergência tecnológica entre a produção de computadores e de equipamentos de telecomunicações, que facilitou a interpenetração (ou acelerou a concorrência) interindustrial.

$\mathrm{Na}$ indústria aeroespacial, a dominância das empresas americanas vincula-se ao projeto de hegemonia político-militar dos EUA. Neste país, o enorme esforço de P\&D, mantido em $75 \%$ por créditos estatais através da NASA, e os programas da US Air Force para racionalização dos componentes do setor, garantem o domínio de tecnologias de ponta e o desenvolvimento das atividades de engenharia de sistema e de aplicação, vitais à aeroespacial.

As indústrias de bens intermediários e insumos (metalurgia e química) apresentam uma problemática específica de reestruturação. A siderurgia, nos anos 70, era uma indústria que reclamava uma reordenação espacial e redução de capacidade. Mas, ao mesmo tempo, as demandas cada vez mais qualificadas de algumas indústrias (automobilística, aeroespacial etc.) pressionavam o desenvolvimento de uma grande diversidade de aços e de novas ligas metálicas e, portanto, a adequação qualitativa das metalúrgicas. A saída encontrada pelas empresas metalúrgicas dos 
países centrais tem sido a redução de capacidade das siderúrgicas tradicionais, deslocando, assim, para a periferia do sistema aquelas atividades intensivas em energia e poluição, e reciclando seus parques para o atendimento de demandas especializadas das indústrias metal-mecânicas.

A indústria química podia ser considerada madura em termos de processos e produtos, na maior parte de seus encadeamentos para trás, onde as regras de concorrência tornaram-se, por isso, estabilizadas e banalizadas. Entretanto, apresentava um potencial revolucionário em seus desdobramentos para frente, para as áreas de química fina e biotecnologias.

\section{A GEOPOLÍTICA DO CAPITALISMO}

Os movimentos de reestruturação em curso estão levando ao rompimento de mercados consolidados durante o ciclo expansivo do pós-guerra e à redefinição da concorrência intercapitalista tanto no nível das empresas quanto no nível dos Estados nacionais. Um balanço dos processos nacionais de reestruturação aponta o japonês como o de mais êxito no sentido de eliminar sobrecapacidade das indústrias em declínio, de promover as indústrias dinâmicas da nova trajetória mecatrônica e de modernizar e racionalizar os processos de produção e de trabalho. A maior competitividade das indústrias japonesas explica-se pela integração da estrutura industrial, que possibilitou tanto a difusão das novas tecnologias e de formas alternativas de organização do processo de trabalho, quanto a obtenção de sinergias e de economias de escopo importantes.

Algumas interrogações colocam-se, contudo, sobre as perspectivas do padrão de reestruturação japonês e sobre o papel que este país desempenhará na nova ordem mundial, que ora se gesta. A primeira refere-se ao dinamismo interno desta economia, centrado, nos últimos anos, principalmente nas exportações do completo mecânico-eletrônico. A liderança tecnológica japonesa em importantes segmentos da mecatrônica, da robótica, da eletrônica de consumo tem aumentado significativamente o superávit comercial japonês com os EUA, a CEE e os tigres asiáticos. Com relação aos EUA e à CEE, a manutenção destes superávits dependerá de outros condicionantes, cujos contornos não estão, ainda, precisos.

Há um certo consenso quanto à impossibilidade de se manter por algum tempo os atuais níveis de desequilíbrio entre o Japão e os EUA. Dificilmente os EUA poderão continuar a ser o país-locomotiva do comércio internacional como nos últimos anos. Neste sentido, o Japão estará obrigado a assumir um papel de maior liderança internacional, a despeito das restrições que continuam lhe sendo impostas pelos EUA e a Europa Ocidental. 
É do interesse dos japoneses atuar, nos próximos anos, de forma a estimular o crescimento de sua economia e do comércio internacional. Isto tende a aproxima-los dos EUA. Tal situação não garante, no entanto, que os japoneses, em caso de agravamento da crise, não venham a ser tomados como concorrentes desleais e indesejáveis. (Torres, 1988)

Uma segunda questão em relação ao papel que o Japão desempenhará na próxima década diz respeito à concorrência entre seus conglomerados e as corporações americanas em termos de produção de pesquisa básica. As evidencias até agora são no sentido de que, neste terreno, o peso do orçamento americano continue a garantir a hegemonia de suas corporações. As propostas enfáticas dos EUA na Rodada do Uruguai para incluir no âmbito do GATT o comércio de tecnologia, a propriedade intelectual e os serviços de engenharia constituem uma pista da importância da produção de novas tecnologias para sua estratégia de médio e longo prazos.

Por último, cabe destacar que a internacionalização do capital financeiro e mercantil japonês na década de 80 constitui fato inédito na história daquele capitalismo. Durante todo o ciclo expansivo do pós-guerra e a reestruturação dos anos 70, coube ao capital financeiro japonês financiar os investimentos dos conglomerados japoneses, sobretudo no mercado interno. A menos que o governo japonês retome sua concepção de política econômica dos anos 70, promovendo a expansão do consumo das famílias, do investimento público e abrindo frentes para o investimento privado interno, os superávits com o exterior continuarão a financiar o déficit público americano, a comprar siderúrgicas nos EUA, a reestruturar a economia do Reino Unido etc.

No que tange à Comunidade dos Doze, os principais países membros, obedecendo a estratégias de ajustamento diferentes, realizaram mudanças na estrutura de suas economias. Todavia, todas as estratégias tiveram âmbito nacional. Dados a profundidade da crise europeia, o caráter de bloco dos projetos americano (integração progressiva das economias americana, canadense e mexicana) e japonês (Japão, Coreia, Hong Kong e, para a próxima década, talvez, a China) e o acirramento da concorrência internacional, as estratégias dos principais países europeus revelaram-se muito limitadas. As duas propostas de reestruturação industrial - política de complexos e política de nichos - resultaram no privilégio de empresas nacionais líderes, dos "campeões de indústria" de cada país. Este resultado acirrou a concorrência entre as empresas europeias, que passaram a intensificar acordos de cooperação técnica e de produção com empresas japonesas e americanas como forma de ganhar parte dos mercados dos campeões vizinhos. Esta política acabou por reforçar a posição de mercado de alguns conglomerados japoneses da eletrônica e de equipamentos flexíveis estandardizados. 
Outra limitação das estratégias europeias refere-se ao montante de investimento e ao requerimento e escalas técnicas de produção para viabilizar as indústrias de eletrônica profissional, de telecomunicações, aeroespacial e de equipamentos flexíveis, dificilmente alcançáveis dentro de cada uma das economias da CEE. Assim, apesar de os principais países da Comunidade terem reconvertido segmentos importantes de bens de consumo, restam sobrecapacidades consideráveis em alguns segmentos de metalúrgica e da química, e os avanços em alguns segmentos definidores do nível de produtividade sistêmica estiveram aquém dos alcançados pelos japoneses e americanos. Este tem sido para os capitalistas europeus o custo da "não Europa".

Em 1985, vários fatores pesaram a favor da proposta de viabilização plena do mercado europeu único, em 1992. A dificuldade de concretizar um ajuste estrutural da Comunidade a partir das experiências nacionais era ponto relevante. Destacavam-se, ainda, a não competitividade dos "campeões nacionais" de grande parte dos segmentos das indústrias mecânica e eletrônica; a necessidade de explorar as economias de escala e de escopo de um mercado com 322 milhões de pessoas e com um PIB de US\$ 4,4 trilhões, sem tarifa aduaneira, com mobilidade da força de trabalho e do capital. Por fim, a unidade monetária europeia era vista como uma resposta às mudanças que vinham ocorrendo nos mercados financeiros internacionais.

Algumas medidas já foram assentadas: a abertura dos mercados públicos, a supressão dos controles aduaneiros e a liberalização dos serviços financeiros, em 1990. Estas medidas, quando efetivadas, acarretarão mudanças na estrutura de mercado da Europa dos Doze e nas formas de regulação econômica dos Estados nacionais. A abertura dos mercados públicos nacionais, que representam $8,5 \%$ do PNB da Comunidade, acirrará a concorrência nas indústrias de telecomunicações, transporte e energia. Provavelmente sobreviverão as empresas mais eficazes dos segmentos em que cada um dos países tenha ou possa rapidamente adquirir vantagens comparativas no contexto do mercado único. A supressão das tarifas alfandegárias determinará a substituição de produções nacionais por importações da Comunidade, redefinindo os mercados de bens de consumo e intermediários. A livre circulação de capitais permitirá a todo cidadão da CEE ter conta bancária em qualquer Estado-membro, procurar nos diversos países as melhores taxas para empréstimos, e às empresas operarem nas bolsas dos dozes países e investirem nos mercados internacionais mais promissores.

Do ponto de vista da estrutura de mercado, as medidas preparatórias de 1992 deverão induzir mudanças nas estratégias das grandes empresas europeias. Favorecem, em princípio, a concentração industrial, a europeização de segmentos nacionais e uma realocação da produção de bens e serviços entre os doze países envolvidos. Entretanto, a definição mais precisa deste cenário dependerá da resposta dos conglomerados 
japoneses e das corporações americanas à estratégia de mercado europeu único. Os EUA, Canadá e México formarão, de fato, um bloco econômico, suprimindo tarifas aduaneiras, favorecendo a mobilidade do capital e do trabalho, integrando e especializando suas estruturas de produção? O Japão, Coreia do Sul, Cingapura e Hong Kong seguirão um caminho próximo? Teremos um fim de século tripolarizado em termos econômicos? Ou, ao contrário, os países capitalistas avançados caminham para a interdependência de suas economias, a internacionalização de suas estruturas de produção e de circulação, como sugerem os acordos de tecnologia e de produção entre os conglomerados japoneses e empresas americanas e europeias, a expansão internacional do mercado financeiro japonês e a "proposta comum" dos países desenvolvidos na Rodada do Uruguai do GATT? Essas são questões ainda em aberto.

Com relação aos EUA, o atual presidente americano deverá implementar um programa de ajuste macroeconômico voltado para a diminuição do déficit em conta corrente. Na medida em que os EUA absorvem 22\% das exportações japonesas e 19\% das da CEE, o papel do comércio exterior deste país como motor do crescimento terá que ser revisto. Neste caso, estariam a Alemanha Ocidental e o Japão dispostos a dividir este papel? Além disso, o comando da política monetária norte-americana pelo FED tentará evitar a aceleração inflacionária, favorecendo elevações na taxa de juros. E quanto mais difícil seja para a atual administração conter o déficit fiscal, maiores serão os aumentos da taxa de juros e mais voláteis tornar-se-ão as taxas de câmbio.

O cenário provável para a economia norte-americana, com a eleição de Bush, está mais para um ajustamento macroeconômico através da manipulação dos juros e do câmbio do que para um programa de ajuste do déficit fiscal a partir de cortes nos gastos governamentais e elevação de impostos. Neste contexto, ficam pendentes algumas questões. Qual a implicação do encontro de cúpula URSS/EUA, em 1987, sobre desarmamento nuclear, nos programas de defesa americana? Que prioridades terão os orçamentos fiscais americanos neste final de década? Se os gastos de defesa sofrerem solução de descontinuidade, quais serão os efeitos desta sobre os segmentos de tecnologia de ponta da economia americana? Como serão resolvidos os problemas das indústrias em declínio nos EUA? Com mais barreiras não tarifárias? Internacionalizando estes segmentos, como está ocorrendo com parte da siderúrgica, que está sendo adquirida por capitais japoneses? Qual a importância para a reconversão do sistema produtivo americano da inclusão no âmbito do GATT do comércio de tecnologia, da propriedade intelectual e dos serviços financeiros e de engenharia? Conseguirão os países desenvolvidos harmonizarem seus interesses sobre estas atividades do futuro? Como se darão as relações dos EUA, Japão e o mercado único europeu? A extensão e profundidade das questões a serem enfrentadas pelas economias capitalistas avançadas remetem para um futuro ainda 
distante a possibilidade de articulação dos interesses necessários à redefinição das rotinas de funcionamento do capitalismo e do conjunto de regras e instituições que as presidem.

Apesar de algumas indefinições sobre o caráter das articulações dos intra e interblocos, sobre a interdependência das economias dos países desenvolvidos e a respeito das estratégias das transnacionais, que afetarão as rotinas futuras de funcionamento do capitalismo, tudo leva a crer que o esboço da nova ordem político-econômica, que ora se desenha, não inclui nenhum papel específico para a América do Sul, África e parcela significativa da Ásia. Esta exclusão é detectada tanto no nível da política de investimentos das transnacionais quanto das estratégias geopolíticas do Grupo dos Cinco.

Observa-se, a partir do final dos anos 70, uma concentração dos investimentos diretos e dos contratos de cooperação técnica e de produção das transnacionais nos EUA, Europa e Japão. Tomando a América do Sul como exemplo, observa-se que entre 1981 e 1984 os investimentos diretos do exterior caíram 60\% em termos nominais, atingindo, em 1984, o mesmo nível real de 1974. Considerando os investimentos diretos e os contratos de cooperação técnica como as formas principais de difusão de progresso técnico nos países centrais, a exclusão dos países de menor desenvolvimento das áreas de inversão, num período de rápida mutação tecnológica, significa que a estratégia das transnacionais seja a de concentrar as novas indústrias dinâmicas, intensivas em conhecimento, nos países centrais. Nesta hipótese, caberiam aos países de menor desenvolvimento relativo aqueles segmentos intensivos em insumos locais, energia e de tecnologia difundida e banalizada.

Do ponto de vista do Grupo dos Cinco, a proposta deste de incluir o comércio de tecnologia, a propriedade intelectual, os serviços de engenharia e financeiros no âmbito do GATT, delineia bem, como já mencionado, quais atividades constituem o cerne do processo de acumulação dos países avançados. Nesta mesma direção, os contenciosos comerciais dos EUA com o Brasil, Índia e Coreia do Sul em relação à informática, à microeletrônica e aos serviços de engenharia ilustram a reserva destes mercados pretendida pelos países centrais. 